\title{
Associations between DSM-IV diagnosis, psychiatric symptoms and morning cortisol levels in a community sample of adolescents
}

\author{
Robert Young • Helen Sweeting • Patrick West
}

Received: 24 March 2010/Accepted: 21 March 2011/Published online: 8 April 2011

(C) The Author(s) 2011. This article is published with open access at Springerlink.com

\begin{abstract}
Purpose Dysfunction of the hypothalamic-pituitaryadrenocortical axis (HPA-axis) is implicated in a variety of psychiatric and emotional disorders. In this study, we explore the association between HPA-axis functioning, as measured by morning cortisol, and common psychiatric disorders and symptoms among a community sample of adolescents.

Method Data from a cross-sectional school-based survey of 501 school pupils, aged 15 , were used to establish the strength of association between salivary morning cortisol and both diagnosis of psychiatric disorders and a number of psychiatric symptoms, as measured via a computerised psychiatric interview. Analysis, conducted separately by gender, used multiple regressions, adjusting for relevant confounders.

Results With one exception (a positive association between conduct disorder symptoms and cortisol among females) there was no association between morning cortisol and psychiatric diagnosis or symptoms. However, there was a significant two-way interaction between gender and conduct symptoms, with females showing a positive and males a negative association between cortisol and conduct symptoms. A further three-way interaction showed that while the association between cortisol and conduct symptoms was negative among males with a few mood disorder symptoms, among females with many mood symptoms it was positive. Conclusions Except in relation to conduct symptoms, dysregulation of morning cortisol levels seems unrelated to any psychiatric disorder or symptoms. However, the
\end{abstract}

R. Young $(\bowtie) \cdot$ H. Sweeting $\cdot$ P. West

MRC Social and Public Health Sciences Unit,

4 Lilybank Gardens, Glasgow G12 8RZ, UK

e-mail: robert@sphsu.mrc.ac.uk relationship between cortisol and conduct symptoms is moderated by both gender and mood symptoms. Findings are compatible with the recent work suggesting research should concentrate on the moderated associations between gender, internalising and externalising symptoms and cortisol, rather than any simple relationship.

Keywords Morning cortisol · Stress · DSM-IV ·

Psychiatric diagnosis · Psychiatric symptoms · Adolescents

\section{Introduction}

The hypothalamic-pituitary-adrenocortical axis (HPA-axis) system is involved in the regulation of the stress response. Dysfunction of this system is implicated in a variety of psychiatric and emotional disorders, including negative effect, depression, anxiety, chronic fatigue and developmental psychopathology [1]. The exact nature of this relationship is unclear. It could be causal (chronic stress impairing HPA-axis functioning), developmental (early trauma disrupting the HPA-axis) or a consequence of psychiatric problems.

HPA-axis (dys)functioning has typically been assessed via cortisol, which can be measured in a number of ways (via saliva, urine or blood plasma) which are highly correlated. Because of ease of collection, salivary cortisol is the most widely used [2-4]. The complicated nature of 'normal' cortisol functioning makes defining what is regarded as an abnormal level or dysregulated cortisol system difficult. It has been assessed either in relation to its reactivity to an induced stressor, activity through its daily circadian cycle, or over shorter periods such as the cortisol awakening response [5], or via basal (i.e. unstressed) output at key times, loosely grouped into morning, midday or 
afternoon, and evening levels [2-4]. One operationalisation of 'abnormal' is a significant departure (either hypo or hypersecretion) from the basal levels expected during the circadian cycle. Amid a multitude of methods and potential collection times, morning cortisol is one of the most common measures used in relation to psychiatric outcomes. This study examines how basal (morning) salivary cortisol levels are related to major Diagnostic and Statistical Manual of Mental Disorders, Fourth Edition [DSM-IV] [6] diagnoses and psychiatric symptoms in a community sample of adolescents.

Box 1 outlines the expected relationship between cortisol and various psychiatric disorders drawn from the past literature, focusing on the pattern for morning cortisol and likely mechanisms involved, and the following text briefly reviews the evidence for these predictions. These predictions are drawn from both the adult and adolescent literature since the majority of existing studies focus on adults. With the exception of depression, both adult and adolescent predictions are generally consistent.

Following the few meta-analyses which have examined the cortisol/psychiatric relationship, we restrict our focus to major mechanism and we outline selected examples of the past and recent work for major disorders [7-10]. This is a fast evolving field with many emerging intricate biopsychosocial theories linking HPA-axis/cortisol and psychiatry, for example neurogenesis and depression [11, 12] or allostatic load and mood disorder [13]. We cannot directly test such intricate theories and concentrate on more general associations with psychopathology.

\section{Cortisol and anxiety}

Since cortisol production is intrinsically linked to stress, individuals with anxiety disorders can plausibly be expected to show abnormal basal levels. It is assumed that anxiety prone individuals either have an oversensitive stress response or, due to features of particular anxiety disorders, such as hypervigilance, experience more stressors than those not anxiety prone [14]. Some evidence supports this view, one study of pre-pubertal children with anxiety disorders finding elevated daytime (morningthrough-evening) and reduced night-time levels [15], and several studies finding elevated morning $[16,17]$ or daytime $[16,18]$ cortisol levels among adolescents with anxiety problems. However, the evidence-base is far from consistent, a recent population-based study of older adults with a variety of anxiety disorders and a history of trauma demonstrating lower midday and evening, but not morning, levels of cortisol, than controls [19]. One relatively consistent finding is that both adults and adolescents with phobic disorders (social phobia, specific phobia) show normal basal cortisol levels [20-23]. Since the extreme stress experienced by phobic patients is triggered by very specific stimuli, which elicit a context specific stressreaction, phobic disorders may be unrelated to general dysregulation of the HPA-axis. Findings for less common anxiety disorders are again inconsistent, although there is some evidence that levels of cortisol are elevated in both adults and adolescents with more pervasive anxiety disorders or problems such as attachment disorder/problems [24, 25], panic disorder or agoraphobia [26-29] or obsessivecompulsive disorder [30-32].

\section{Cortisol and post-traumatic stress}

Given the link between exposure to stress and cortisol, basal levels of cortisol have been extensively investigated in relation to post-traumatic stress disorder (PTSD) and trauma in general. The most comprehensive studies have
Box 1 Relationship between morning cortisol and disorder and possible mechanisms derived from the literature

$\uparrow$ Higher cortisol than controls

$\downarrow$ lower cortisol than controls

$=$ no difference

? no clear prediction

\begin{tabular}{lll}
\hline Psychiatric disorder & $\begin{array}{l}\text { Association } \\
\text { with morning } \\
\text { cortisol }\end{array}$ & Mechanism \\
\hline
\end{tabular}

\begin{tabular}{lll}
\hline Anxiety (GAD) & $\uparrow$ & Oversensitive HPA system or intermittent stress activation \\
Social phobia & $=$ & Situation specific \\
Separation anxiety & $=$ & Situation specific \\
Specific phobia & $=$ & Situation specific \\
Panic or agoraphobia & $\uparrow$ & Oversensitive HPA system or intermittent intense stress reaction \\
OCD & $\uparrow$ & Constant stress leads to continuously elevated cortisol levels \\
PTSD/trauma & $\downarrow$ & Flattened HPA-axis \\
Depression & $\downarrow$ Adult & Multiple theories: e.g. neurogenesis, constant stress leads to \\
& $?$ Youth & changes in HPA and psychoneuroendocrinology \\
& functioning and brain structure \\
ADHD & $\downarrow$ & (Under) arousal theory \\
Conduct/ODD & $\downarrow$ & (Under) arousal theory; fearlessness theory \\
\hline
\end{tabular}


focused on adult samples, a recent meta-analysis of 37 studies finding no overall systematic difference in basal levels between adults with PTSD and controls [9]. Intriguingly, in a subgroup comparison, lower cortisol levels were found among PTSD patients compared with controls not exposed to trauma, while PTSD patients and trauma-exposed controls were no different. The authors conclude that it may be trauma exposure alone that lowers cortisol levels rather than development of PTSD. A complementary meta-analysis of stress and adult HPA-axis function also found trauma was associated with a small, but significant, reduction in morning cortisol levels [10].

Findings linking extreme trauma to cortisol among children and adolescents are mixed [33, 34]. For example, a study of adopted Romanian orphans found they had elevated morning and evening levels [35]. However, consistent with the adult literature, a study of Armenian adolescents found that even 5 years after exposure to a major natural disaster (earthquake), those closer to the epicentre had lower morning cortisol than those who experienced less trauma [36].

\section{Cortisol and depression}

Cortisol is proposed as one chain in the causal mechanism in the development of depressive disorders [11, 12]. Initially, cortisol hypersecretion was linked with depression, but this view is being revised by a [12] recent work providing greater evidence for cortisol hyposecretion in depressed adults. A community study found currently depressed women had lower (particularly lower morning) cortisol levels than non-depressed controls [37]. Other studies find more mixed results, but a meta-analysis of the cortisol stress-response concluded that morning levels are substantially lower among those suffering from a major mood disorder than controls [8]. In contrast, this effect has not been reliably found in adolescents [15, 38-41].

\section{Cortisol and externalising disorders}

Externalising disorders have also been (inconsistently) linked with low cortisol levels. There are two prominent explanations for this, 'fearlessness theory' [42] and (low) autonomic arousal $[7,43]$. The first suggests that low fear, marked by low cortisol levels, is a factor in externalising disorders. The second 'autonomic arousal theory' suggests that low cortisol may be a symptom of chronically low basal arousal levels, affected individuals being motivated to raise arousal to a tolerable level by seeking out novel and stimulating experiences, which in turn results in increased externalising behaviours [7].

In adults, criminal and aggressive behaviour has been linked to low morning cortisol [44]. The phenomenon has also been studied extensively in children and adolescents [7], a systematic review of 59 studies concluding that there is a small, but significant, inverse association between basal cortisol levels and externalising behaviour [7]. However, this effect varied considerably, with larger effects among males, clinical samples, those with a diagnosis of ADHD, older adolescents or samples heterogeneous in age. Smaller effects were found in those with a diagnosis of oppositional-defiant (ODD) or conduct disorder (CD) and when analyses were conducted without covariates or a suitable log-transformation of cortisol. The review concluded that, due to considerable variation between studies and large confidence intervals, all these moderator effects should be considered trends, rather than conclusive results. However, they do provide a useful account of contextual and study design factors which should be considered when investigating this area.

Methodological considerations in studies of cortisol and psychiatric diagnoses

Four separate systematic reviews of cortisol and psychiatric disorders or stress [7-10] have highlighted the limitations of past research in this area. These include a focus on small (often single sex, or clinic-based) convenience rather than population samples, use of wide age bands, differences between psychiatric diagnosis and general symptoms, limited consideration of co-morbidity, and a lack of control for potential confounders or mediators of cortisol such as gender.

As a consequence of these limitations, only a few studies have the power to systematically explore interactions between gender, symptom severity or co-morbidity. In relation to gender, a recent general population study of Dutch 10-12 year olds demonstrated a negative association between antisocial behaviour and morning cortisol for boys, but a positive relationship for girls [45]. A further analysis contrasted four groups of adolescents; those with no problems, only internalising problems, only externalising problems, or both (co-morbid group), finding no difference in morning cortisol levels [46]. Additional analysis revealed that girls with only externalising problems had significantly higher morning cortisol than all other groups. Due to the inconsistent findings from past research, the authors are understandably cautious in drawing strong conclusions, stressing the importance of replication and inclusion of these factors in the future work. Among the potential explanations for gender-related differences in the aetiology of CD, Keenan and Shaw [47] proposed two childhood pathways to later adolescent conduct problems. The first is the reactive/over-arousal pathway, suggesting that oversensitive children, who have inherent difficulties in coping with negative emotions, are at risk. The second is 
the proactive/under-arousal pathway in which under-sensitive, and sensation seeking and disruptive children are also at risk. They hypothesised that difference in socialisation result in a greater proportion of $\mathrm{CD}$ boys on the proactive/under-arousal path, while the majority of girls take the reactive/over-arousal one. While they do not specifically link this explanation to cortisol, this model is compatible with the Dutch findings of lower morning cortisol levels in antisocial boys but higher levels in antisocial girls [45].

We report results from a school-based study of adolescents designed to investigate the links between morning cortisol and psychiatric (DSM-IV) diagnosis or symptoms. In this study we aim to establish if, after controlling for appropriate confounders [48], the pattern between psychiatric diagnosis and cortisol matches as suggested in the literature (Box 1). Broadly, we predict general anxiety disorder (diagnosis and symptoms) will be directly associated (i.e. elevated cortisol levels); anxiety disorders with very specific triggers (e.g. specific phobia) will be unrelated; and externalising, depression and PTSD disorders will be inversely associated with morning cortisol. We also explore interactions between gender and psychiatric comorbidity as suggested by a recent research $[45,46]$.

\section{Methods}

Study participants and procedures

Data come from a subsample of 501 pupils (mean age 15.3 years) in four schools. These four schools were surveyed as part of a larger study of 22 schools and were selected for in-depth psychiatric investigation. In addition to our main study measures, pupils in the subsample completed a computerised, DSM-IV compatible, audio version of the Diagnostic Interview Schedule for Children (DISC) [49], the Voice-DISC [50, 51]. We report the details and design of the larger study elsewhere [48, 52], and provide only a brief summary here. The larger study surveyed $(3,194)$ pupils within 22 schools situated in predominantly urban areas in and around Glasgow city in the West of Scotland. All pupils in the final statutory year of schooling were invited to participate via a two-stage consent procedure, combining parental opt-out and pupil opt-in via signed consent on the day of the study. Glasgow University Ethics Committee, local authorities and participating schools approved the study.

The full sampling scheme aimed to obtain (and largely achieved) a stratified sample representative of the local area based on geographical location, religious status and area deprivation [48]. The subsample of interest here is broadly comparable with the larger sample. In addition, probabilistic weights to compensate for non-responders were derived, but subsequent analyses found no substantive differences in results using weighted and unweighted data. In consequence we use the latter.

The survey component took place in school-based sessions during the first morning class (approximately 09.00-09.50 h). Pupils completed a questionnaire and provided two salivary cortisol samples (30 min apart). The psychiatric component took place within a day of the survey. 562 pupils ( $93 \%$ of the total target subsample) completed a questionnaire and provided valid cortisol samples, of whom $501(89 \%)$ completed all relevant components of the voice-DISC.

\section{Voice-DISC administration}

Due to the psychiatric nature of the Voice-DISC, additional procedures were necessary to comply with ethical and practical concerns, full details of which are available elsewhere [53]. Briefly, the interview was administered to groups of up to 80 pupils in supervised classroom settings with pupils allowed to complete the program in their own time. Unobtrusive flags within the Voice-DISC alerted staff if a participant reported serious physical or sexual abuse, or a recent suicide attempt or suicidal ideation. In such cases, participants were directed to a psychiatric nurse at the session end.

\section{Measures}

\section{Cortisol}

Cortisol was obtained using a Salivette sampling device around 5 and 35 min into questionnaire completion when the whole group was instructed to chew on a cotton swab for approximately $2 \mathrm{~min}$, after which completed samples were collected (details available) [48]. Samples were analysed using the IBL luminometric assay (IBL, Hamburg, Germany) and approximately $10 \%$ were run in duplicate for assessment of inter-assay (all values $<8 \%$ ) and intraassay reliability (all values $<5 \%$ ). Cortisol was examined as absolute levels which were logged for analysis. Practical and budgetary restrictions limited our HPA-axis measure to two closely timed morning cortisol samples. Morning cortisol is considerably more reliable $(r \approx .6$ over several days) than even marginally later $(r \approx .2$, midday) measures [54]. We focus on our first measure because, in addition to being more reliable, using average cortisol from different time points could introduce complications into any analysis, e.g. averaging overlooks the potential that cortisol may have different effects at different times of the day [55]. 
DSM-IV diagnosis and symptoms

The choice of the Voice-DISC was influenced both by study design, our prior experience with the instrument and its capacity to be administrated to large groups of pupils in a school setting [53]. It is a replica of the interviewer version of the DISC and preliminary work suggests it is at least as reliable [56]. Respondents self-administer the interview in interaction with a voice, using a laptop computer. Following an introduction, the Voice-DISC interview proceeds through a series of modules, with subsections related to specific diagnoses. Questions are asked to establish the presence of symptoms, their severity and duration, and the extent to which they cause distress and/or impairment. Disorders included in this study comprise eight anxiety (social phobia, separation anxiety, specific phobia, agoraphobia/panic, general anxiety, selective mutism, obsessive compulsive and PTSD), two depressive (major depressive and dysthymia), and three externalising (ADHD, ODD and CD) disorders. Several disorders were excluded: alcohol and substance use, due to time constraints; schizophrenia on the grounds of inappropriateness; and certain miscellaneous disorders due to their inappropriateness at the age 15 (e.g. elimination disorder).

Voice-DISC produces present-state (previous 4 weeks) diagnoses via computer algorithms defined in accordance with DSM-IV criteria [57]. In common with previous studies, diagnosis based on symptom criteria produced elevated prevalence rates [51]. However, adding impairment criteria (impairment $\mathrm{A}$-any impairment in one area of functioning) reduces these to more plausible levels. Here we present rates base on both symptom and impairment criteria. Associations with cortisol are based on symptom criteria since results based on impairment criteria were almost identical. In addition the Voice-DISC produces a more nuanced symptom count for several disorders, based upon a wider set of interview responses.

Data analysis

Analysis used multiple regressions with the first morning measure (logged) of salivary cortisol as the primary outcome. Analyses were adjusted for biological confounds identified in a prior study (time since awakening, time of collection, age, body mass index and physical maturity) [48]. Analyses were conducted separately for each gender, with the exception of specific diagnoses where this was not possible due to low numbers. Each specific psychiatric diagnosis was entered as a dummy variable in a series of separate analyses; co-morbidity (interactions) between broader diagnostic categories was examined using three dummy variables (only anxiety or mood disorder, only externalizing disorder, or both, with no-diagnosis as a reference category). Because only two cases received an exclusive mood disorder diagnosis, anxiety and mood disorder were combined for certain analyses. Psychiatric symptom counts were analysed in a similar manner, but with symptom count entered as a continuous variable.

Interactions between mood and conduct symptoms were explored using a model which included both main effects (after centering) and their interaction. Interactions between gender and each broad diagnostic category were also explored. Significant interactions can be difficult to interpret and although graphing can aid when the interaction involves discrete groups, for continuous variables determining the critical level at which a slope is significantly different from zero is complicated [58]. We used the online tools by Preacher, Curran and Bauerto [59] to determine this critical level and to produce interaction plots which are adjusted for covariates. Significant two-way interactions are illustrated by plotting the slopes between each symptom count and cortisol for each gender, or at meaningful symptom levels. Significant three-way gender interactions are illustrated by plotting the slope between cortisol and the first variable at meaningful levels of the second variable for each gender. In the absence of any clear guidelines, we plot symptom scores with values +1 and -1 standard deviations (SD) from the mean.

To ensure our results were robust, we reanalysed the data excluding the few multivariate (Mahalanobis distances) outliers and influential residual cases; this made no substantial difference. Many of the symptom counts were non-normally distributed and a series of transformations were applied to better approximate the normal distribution. While the transformed variables made slight improvements to the model fit and significance levels, this was marginal, and so only untransformed results are reported. Power calculations suggest we have over $80 \%$ power to detect a small association ( $N=501, r=.13, p<.05$, two-sided $)$.

\section{Results}

Psychiatric diagnosis

The prevalence ( $N$ and \%) of each psychiatric disorder and of (major) anxiety, mood and behavioural disorders using symptom and impairment criteria are shown in Table 1 . The prevalence rates are broadly comparable with those reported in our earlier Voice-DISC study of Scottish adolescents [51]. Only results of regression analyses for symptom criteria are reported in Table 1 since results using impairment were substantively no different. Adjusting for relevant confounds, no disorder was associated with morning cortisol, nor was there any indication of an interaction (co-morbid) effect. Separate analyses for each 
Table 1 Basic prevalence of psychiatric disorders and their association with morning cortisol

\begin{tabular}{|c|c|c|c|c|c|c|c|c|}
\hline \multirow[t]{3}{*}{ Diagnosis } & \multicolumn{4}{|c|}{ Prevalence } & \multirow{2}{*}{\multicolumn{4}{|c|}{$\begin{array}{l}\text { Regression } \\
\text { Symptom criteria predicting morning cortisol }\end{array}$}} \\
\hline & \multicolumn{2}{|c|}{ Symptom criteria } & \multicolumn{2}{|c|}{ Impairment criteria } & & & & \\
\hline & $N$ & $(\%)$ & $N$ & $(\%)$ & $B$ & SE & $\beta$ & $p$ \\
\hline \multicolumn{9}{|l|}{ Anxiety disorders } \\
\hline Social phobia & 23 & 4.6 & 17 & 3.4 & -.011 & .047 & -.010 & .813 \\
\hline Separation anxiety & 21 & 4.2 & 11 & 2.2 & -.023 & .050 & -.019 & .641 \\
\hline Specific phobia & 39 & 7.8 & 11 & 2.2 & .005 & .038 & .006 & .889 \\
\hline Agoraphobia/panic attacks & 19 & 3.8 & 8 & 1.6 & -.035 & .053 & -.027 & .513 \\
\hline General anxiety disorder & 4 & .8 & 4 & .8 & $*$ & & & \\
\hline Selective mutism & 3 & 6 & 1 & .2 & $*$ & & & \\
\hline Obsessive compulsive disorder & 30 & 6.0 & 20 & 4.0 & .034 & .042 & .033 & .425 \\
\hline Post-traumatic stress disorder & 2 & .4 & 2 & .4 & $*$ & & & \\
\hline Major mood/dysthymic disorder & 9 & 1.8 & 8 & 1.6 & .019 & .074 & .011 & .794 \\
\hline \multicolumn{9}{|l|}{ Behavioural disorders } \\
\hline Attention-deficit hyperactivity disorder & 6 & 1.2 & 6 & 1.2 & -.003 & .090 & -.002 & .971 \\
\hline Oppositional defiant disorder & 19 & 3.8 & 17 & 3.4 & -.024 & .053 & -.018 & .651 \\
\hline Conduct disorder & 19 & 3.8 & 10 & 2.0 & -.054 & .052 & -.043 & .298 \\
\hline \multicolumn{9}{|l|}{ Major disorders } \\
\hline Any anxiety/mood disorder & 92 & 18.4 & 51 & 10.2 & -.005 & .027 & -.009 & .841 \\
\hline Any behavioural disorder & 42 & 8.4 & 32 & 6.4 & -.039 & .036 & -.044 & .284 \\
\hline Any disorder & 122 & 24.4 & 74 & 14.8 & -.010 & .024 & -.018 & .668 \\
\hline \multicolumn{9}{|l|}{ Co-morbidity between major disorder } \\
\hline No disorder (ref, dummy variables) & 379 & 75.6 & 427 & 85.2 & - & - & - & - \\
\hline Behavioural disorder only & 29 & 5.8 & 23 & 4.6 & -.021 & .043 & -.020 & .631 \\
\hline Anxiety or mood disorder only & 80 & 16.0 & 42 & 8.4 & .004 & .028 & .007 & .873 \\
\hline Both major disorders & 13 & 2.6 & 9 & 1.8 & -.075 & .063 & -.050 & .233 \\
\hline
\end{tabular}

Regression adjusts for gender, time since awakening, time of collection, age, body mass index and physical maturity. With the exception of the dummy variables reported in the last four rows, each row reports the results of a separate regression analysis. Prevalence based on both DSM-IV symptom criteria and impairment criteria (impairment A-any impairment). Only results for symptom criteria are shown, since results are substantively no different from those using impairment criteria

* Regression analysis omitted due to due to small $N$

gender using broader diagnostic categories (Table 2) revealed a similar null finding. All formal tests for gender interactions were non-significant.

\section{Psychiatric symptoms}

Table 3 reports the association between symptom counts and morning cortisol for each gender. Only CD symptoms in females $(p=.043)$ were associated with elevated morning cortisol levels. A formal test confirmed a significant gender interaction $(p=.02)$. This interaction is illustrated in Fig. 1 which plots the slope between (logged) morning cortisol and the number of conduct symptoms with separate lines for each gender. This shows a significantly positive slope for females $(t=2.12$, $d f=487, p=.03)$, but a flat slope for males $(t=-1.02$, $p=.31)$.
The interaction between mood disorder and conduct symptoms for the total sample was also significant $(p=.021)$. This interaction is illustrated in Fig. 2, which plots the slope between morning cortisol and number of conduct symptoms within the observed range (0-14), with separate lines representing mean mood symptom levels (observed range 0-20 symptoms) 1 SD above and below the mean. There is no association for those with mean $(0$ $\mathrm{SD}, t=1.40, p=.16)$ or elevated ( $+1 \mathrm{SD}, t=.13$, $p=.90)$ mood symptoms, but those with a few ( $-1 \mathrm{SD}$, $t=-1.90, p=.06$ ) mood symptoms had lower cortisol with the critical region of significance close to zero symptoms.

Further analysis by gender found this was only significant for males $(p=.012)$, and a formal test of a three-way mood disorder by conduct symptoms by gender-interaction was also significant $(p=.017)$. This interaction is 
Table 2 Associations between major psychiatric disorders (symptom criteria) and morning cortisol by gender

\begin{tabular}{|c|c|c|c|c|c|c|c|c|}
\hline \multirow[t]{2}{*}{ Diagnosis } & \multicolumn{4}{|l|}{ Male } & \multicolumn{4}{|l|}{ Female } \\
\hline & $B$ & SE & $\beta$ & $p$ & $B$ & SE & $\beta$ & $p$ \\
\hline \multicolumn{9}{|l|}{ Major disorders } \\
\hline Any anxiety & -.068 & .050 & -.078 & .179 & .016 & .032 & .030 & .605 \\
\hline Any behavioural disorder & -.062 & .047 & -.077 & .187 & -.007 & .055 & -.007 & .905 \\
\hline Any disorder & -.053 & .037 & -.083 & .157 & .017 & .030 & .032 & .583 \\
\hline \multicolumn{9}{|l|}{ Major disorder interaction } \\
\hline No disorder (ref) & - & - & - & - & - & - & - & - \\
\hline Behavioural disorder only & -.036 & .051 & -.041 & .486 & .014 & .077 & .011 & .852 \\
\hline Anxiety or mood disorder only & -.036 & .054 & -.039 & .503 & .022 & .033 & .038 & .517 \\
\hline Both major disorders & -.206 & .108 & -.110 & .059 & -.017 & .078 & -.013 & .833 \\
\hline
\end{tabular}

All regressions adjust for time since awakening, time of collection, age, body mass index and physical maturity. All two-way interactions between gender and major disorders are non-significant. The three-way interaction between behavioural and anxiety/mood disorders and gender is non-significant

Table 3 Associations between psychiatric symptoms and morning cortisol by gender and for total sample

\begin{tabular}{|c|c|c|c|c|c|c|c|c|c|c|c|c|c|c|c|}
\hline \multirow[b]{2}{*}{ Symptoms } & \multicolumn{3}{|c|}{ Symptom scores } & \multicolumn{4}{|c|}{ Total sample } & \multicolumn{4}{|l|}{ Male } & \multicolumn{4}{|l|}{ Female } \\
\hline & $R$ & $M$ & $\mathrm{SD}$ & $B$ & SE & $\beta$ & $p$ & $B$ & SE & $\beta$ & $p$ & $B$ & SE & $\beta$ & $p$ \\
\hline Social phobia & $0-12$ & 3.2 & 3.4 & .002 & .003 & .027 & .512 & -.001 & .004 & -.019 & .743 & .004 & .004 & .062 & .284 \\
\hline Separation anxiety & $0-13$ & 1.1 & 1.5 & -.009 & .007 & -.055 & .194 & -.020 & .012 & -.100 & .089 & -.003 & .008 & -.025 & .662 \\
\hline Specific phobia & $0-9$ & .8 & 1.2 & -.002 & .009 & -.009 & .831 & -.006 & .014 & -.024 & .682 & .001 & .011 & .003 & .964 \\
\hline Agoraphobia & $0-4$ & .2 & .6 & -.020 & .018 & -.046 & .261 & -.040 & .030 & -.077 & .186 & -.012 & .022 & -.031 & .592 \\
\hline GAD & $0-12$ & 2.8 & 2.4 & -.002 & .004 & -.022 & .595 & -.004 & .006 & -.041 & .482 & -.001 & -.006 & .019 & .914 \\
\hline OCD & $0-8$ & .8 & 1.1 & -.004 & .009 & -.020 & .632 & -.011 & .013 & -.051 & .380 & -.001 & .012 & -.003 & .958 \\
\hline PTSD & $0-17$ & .4 & 1.6 & -.003 & .006 & -.018 & .675 & .008 & .018 & .026 & .655 & -.003 & .007 & -.026 & .658 \\
\hline Mood disorders & $0-22$ & 4.2 & 3.9 & .001 & .003 & .010 & .810 & .000 & .004 & -.005 & .927 & .001 & .003 & .023 & .696 \\
\hline ADHD & $0-23$ & 4.8 & 4.3 & $<.001$ & .002 & -.003 & .942 & .005 & .004 & .076 & .195 & -.003 & .003 & -.056 & .338 \\
\hline ODD & $0-12$ & 3.6 & 2.8 & .002 & .004 & .024 & .561 & -.002 & .005 & -.020 & .733 & .006 & .005 & .069 & .245 \\
\hline $\mathrm{CD}$ & $0-26$ & 1.9 & 1.5 & .002 & .006 & .014 & .726 & -.008 & .008 & -.064 & .276 & .024 & .012 & .118 & .043 \\
\hline Interaction, conduct and mood & & & & .003 & .001 & .190 & .021 & .008 & .003 & .302 & .012 & -.002 & .003 & -.124 & .449 \\
\hline
\end{tabular}

Mood disorders is a combined (major mood/dysthymic disorder) symptom count

All regressions adjust for time since awakening, time of collection, age, body mass index and physical maturity and the total sample is further adjusted for gender. All two-way interactions between gender and symptoms non-significant, except conduct disorder $(t=-2.3, p=.020)$. Three-way interaction between conduct and mood symptoms and gender, $t=2.4, p=.017$

$R$ possible range (minimum to maximum) of symptom count, $M$ mean symptom count, $S D$ standard deviation

illustrated in Fig. 3, which plots the slope between morning cortisol and the number of conduct symptoms, at $\pm 1 \mathrm{SD}$ levels of mood symptoms and with separate lines for each gender. This shows that among those with many conduct symptoms, females with more mood symptoms have higher morning cortisol levels, while males with fewer mood symptoms have lower levels. We determined the critical levels of mood symptoms at which the slope between cortisol and conduct symptoms becomes significant. The critical slope for females emerged for those with $\geq 6.5$ mood symptoms, while the inverse association for males emerged for those with near average or fewer $(\leq 5.2)$ mood symptoms, i.e. only males with many conduct and a few mood symptoms show lower morning cortisol levels [60, $61]$.

\section{Discussion}

The aim of this study was to explore associations between morning cortisol and psychiatric disorders and symptoms in a community adolescent population. With a few exceptions, related to $\mathrm{CD}$, the overall conclusion is one of a little or no relationship between cortisol and either 


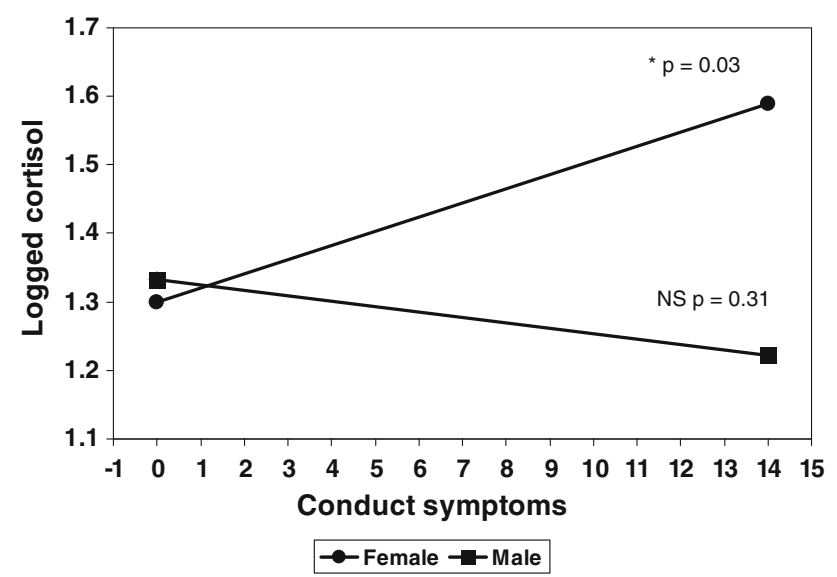

Fig. 1 Slopes for logged morning cortisol according to conduct symptoms by gender

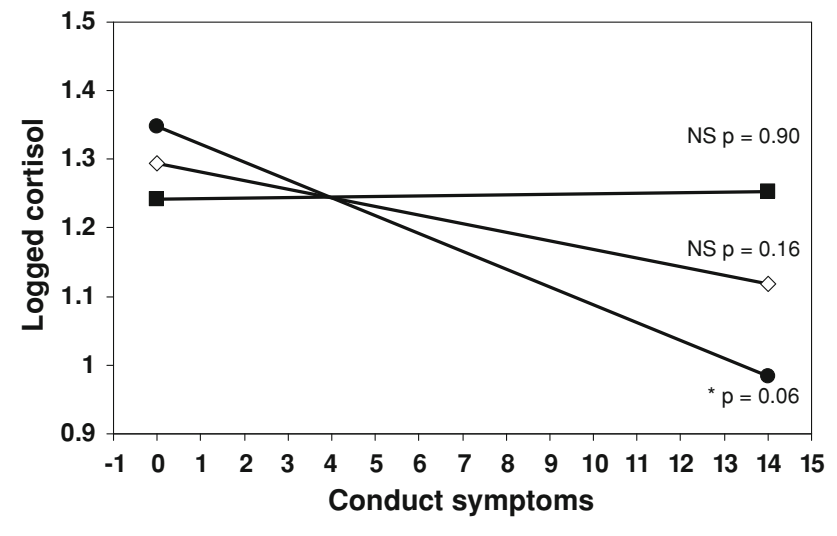

Mood sympt +1 SD $\prec$ Mood sympt 0 SD $\multimap-$ Mood sympt -1 SD

Fig. 2 Slopes for logged morning cortisol according to conduct symptoms for high (+1 SD), average (0 SD) and low ( $-1 \mathrm{SD})$ mood disorder symptoms

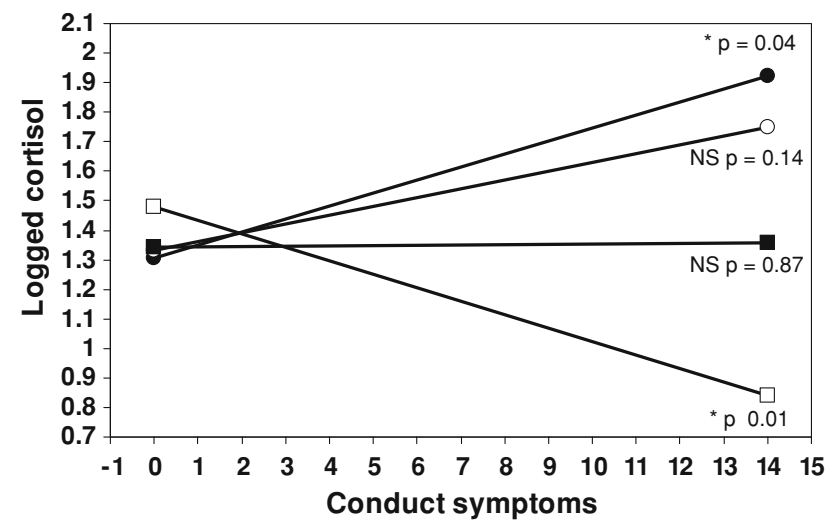

$\rightarrow$ Mood symp +1 SD, female $\multimap-$ Mood sympt-1 SD, female $\rightarrow-$ Mood sympt +1 SD, male $\quad \square-$ Mood sympt -1 SD, male

Fig. 3 Slopes for logged morning cortisol according to conduct symptoms for high (+1 SD) and low ( $-1 \mathrm{SD})$ mood symptoms by gender psychiatric disorders or symptoms. None of our findings support the associations proposed in the (admittedly contradictory), literature. In contrast, our work suggests that any association between psychiatric disorders or symptoms and HPA-axis functioning is complex and involves moderated relationships. This is compatible with current opinion on HPA-axis functioning which asks researchers and clinicians to reconsider initial theories and refute any straightforward connection between cortisol and psychiatric disorders [12].

In relation to depression or anxiety, it may be that among adolescents, dysregulation of the HPA-axis is latent, its effects not being apparent until adulthood [41]. One explanation for the lack of association between PTSD and cortisol is that we have focused on symptoms and not exposure to trauma. This would be consistent with evidence from studies of adults with PTSD that it is exposure to trauma, rather than developing PTSD symptoms (e.g. flashbacks) per se, which is associated with abnormal cortisol levels [9]. However, we did not find an association between trauma (e.g. serious accident) and cortisol in a further analysis of this sample [62].

Despite the broadly negative findings, there is evidence for several moderated relationships between cortisol and psychiatric symptoms, the association between CD symptoms and cortisol differing by gender. While males show an inverse, although not statistically significant relationship, as predicted by fearlessness and (under) arousal theory, females show a direct relationship with CD symptoms. A further interaction between mood and conduct symptoms indicated that among males without mood disorder symptoms, cortisol is inversely associated with CD symptoms. These findings are compatible with the recent developmental research suggesting that each gender typically follows a different pathway in developing conduct problems [47], and empirical evidence from both systematic review [7] and population-based research [45] showing an inverse association only among males.

Among several caveats, ours is not a longitudinal study and so we cannot determine if cortisol is causally implicated in developing symptoms, or if the associations found simply reflect other processes linked to both atypical cortisol levels and psychiatric symptoms. Our focus is on basal (morning) cortisol and other measures (evening, total output, awakening response, stress or reactivity tests) may produce different findings. The use of computerised rather than clinical assessment may be challenged; however from a practical standpoint, one-to-one psychiatrist-led interviews are unfeasible for community-based studies. However, the DISC is a well-recognised standardised and validated psychiatric epidemiological instrument [56]. The study design cannot address all potential biopsychosocial mechanisms linked with vulnerability to stress, including 
the growing evidence of gene-environment interactions related to cortisol functioning [40, 63-65]. Our results are predominantly negative and it is possible the few significant findings are attributable to type 1 error. However, the few significant associations all involve conduct or externalising symptoms, which (of all psychiatric symptoms) are most robustly associated with baseline levels of cortisol. This was a comparatively large population study of adolescents and while this is a considerable strength, the results may not generalise directly to a clinical population, although our findings remain unaltered when impairment criteria are used.

Given the number of studies with inconsistent and contradictory results, our conclusions necessitate a number of caveats. However, while we found scant support for the predictions derived from the literature linking morning cortisol levels with psychiatric disorders, we found some evidence for a set of moderated relationships between gender, co-morbid depression and conduct problems, compatible with the recent research. Our findings suggest that concentrating on these interactions may be one way to resolve the conflicting findings in the literature. They also confirm that because of measurement problems and typically small effect sizes $(\beta \approx .1)$ found in both our own and other studies, a single measure of basal cortisol is unlikely to provide a practical psychiatric diagnostic tool. However, our results remain relevant to psychiatric epidemiological investigation of HPA-axis functioning.

Acknowledgments The work was funded by the Medical Research Council of Great Britain as part of the Youth and Health Programme (WBS U.1300.00.007) at the Social and Public Health Sciences Unit. The authors thank all those who made the 'PaLS' project possible, and all the schools, survey assistants and young people who took part and in particular Shona Kelly our expert advisor on cortisol. We would like to thank Chris Lucas for his invaluable contribution regarding the Voice-DISC interview software.

Ethical standards The study was conducted according to ethical standards. Glasgow University ethics committee, local authorities and participating schools all approved the study. All participants signed consent on the day of the study and a parental opt-out was available.

Conflict of interest The authors declare they have no conflict of interest.

Open Access This article is distributed under the terms of the Creative Commons Attribution Noncommercial License which permits any noncommercial use, distribution, and reproduction in any medium, provided the original author(s) and source are credited.

\section{References}

1. Goodyer IM, Herbert J, Altham PM (1998) Adrenal steroid secretion and major depression in 8- to 16-year olds, III. Influence of cortisol/DHEA ratio at presentation on subsequent rates of disappointing life events and persistent major depression. Psychol Med 28(2):265-273

2. Hellhammer D, Wust S, Kudielka B (2009) Salivary cortisol as a biomarker in stress research. Psychoneuroendocrinology 34(2): 163-171

3. Kelly S, Hertzman C (2001) Finding a stress measure in the literature and taking it into the field. Adv Psychosom Med 22:7-16

4. Kirschbaum C, Hellhammer D (2000) Salivary cortisol. In: Fink G (ed) Encyclopedia of Stress. Academic, San Diego, pp 379-383

5. Chida Y, Steptoe A (2009) Cortisol awakening response and psychosocial factors: A systematic review and meta-analysis. Biol Psychol 80(3):265-278

6. American Psychiatric Association (1994) Diagnostic and statistical manual of mental disorders. 4th edn. Author, Washington

7. Alink LR, van Ijzendoorn MH, Bakermans-Kranenburg MJ, Mesman J, Juffer F, Koot HM (2008) Cortisol and externalizing behaviour in children and adolescents: mixed meta-analytic evidence for the inverse relation of basal cortisol and cortisol reactivity with externalizing behaviour. Dev Psychobiol 50(5):427-450. doi:10.1002/dev.20300

8. Burke HM, Davis MC, Otte C, Mohr DC (2005) Depression and cortisol responses to psychological stress: a meta-analysis. Psychoneuroendocrinology 30(9):846-856. doi:10.1016/j.psyneuen. 2005.02.010

9. Meewisse M-L, Reitsma JB, De Vries G-J, Gersons BPR, Olff M (2007) Cortisol and post-traumatic stress disorder in adults: Systematic review and meta-analysis. $\mathrm{Br} \mathrm{J}$ Psychiatry 191(5):387-392. doi:10.1192/bjp.bp.106.024877

10. Miller GE, Chen E, Zhou ES (2007) If it goes up, must it come down? Chronic stress and the hypothalamic-pituitary-adrenocortical axis in humans. Psychol Bull 133(1):25-45. doi:10.1037/ 0033-2909.133.1.25

11. Jacobs BL, Praag H, Gage FH (2000) Adult brain neurogenesis and psychiatry: a novel theory of depression. Mol Psychiatry 5(3):262-269

12. Varghese FP, Brown ES (2001) The hypothalamic-pituitaryadrenal axis in major depressive disorder: a brief primer for primary care physicians. Prim Care Companion J Clin Psychiatry 3(4):151-155

13. McEwen BS (2000) Allostasis and allostatic load: implications for neuropsychopharmacology. Neuropsychopharmacology 22(2): $108-124$

14. Bar-Haim Y, Lamy D, Pergamin L, Bakermans-Kranenburg MJ, van IJzendoorn MH (2007) Threat-related attentional bias in anxious and nonanxious individuals: a meta-analytic study. Psychol Bull 133(1):1-24. doi:10.1037/0033-2909.133.1.1

15. Feder A, Coplan JD, Goetz RR, Mathew SJ, Pine DS, Dahl RE, Ryan ND, Greenwald S, Weissman MM (2004) Twenty-fourhour cortisol secretion patterns in prepubertal children with anxiety or depressive disorders. Biol Psychiatry 56(3):198-204. doi:10.1016/j.biopsych.2004.05.005

16. Kallen VL, Tulen JH, Utens EM, Treffers PD, De Jong FH, Ferdinand RF (2008) Associations between HPA axis functioning and level of anxiety in children and adolescents with an anxiety disorder. Depress Anxiety 25(2):131-141. doi:10.1002/da.20287

17. McBurnett K, Lahey BB, Frick PJ, Risch C, Loeber R, Hart EL, Christ MA, Hanson KS (1991) Anxiety, inhibition, and conduct disorder in children: II. Relation to salivary cortisol. J Am Acad Child Adolesc Psychiatry 30(2):192-196

18. Greaves-Lord K, Ferdinand RF, Oldehinkel AJ, Sondeijker FE, Ormel J, Verhulst FC (2007) Higher cortisol awakening response in young adolescents with persistent anxiety problems. Acta Psychiatr Scand 116(2):137-144. doi:10.1111/j.1600-0447.2007. 01001.x 
19. Chaudieu I, Beluche I, Norton J, Boulenger JP, Ritchie K, Ancelin ML (2008) Abnormal reactions to environmental stress in elderly persons with anxiety disorders: evidence from a population study of diurnal cortisol changes. J Affect Dis 106(3):307-313. doi:10.1016/j.jad.2007.07.025

20. Alpers GW, Abelson JL, Wilhelm FH, Roth WT (2003) Salivary cortisol response during exposure treatment in driving phobics. Psychosom Med 65(4):679-687

21. Martel FL, Hayward C, Lyons DM, Sanborn K, Varady S, Schatzberg AF (1999) Salivary cortisol levels in socially phobic adolescent girls. Depress Anxiety 10(1):25-27. doi:10. 1002/(SICI)1520-6394(1999)10:1

22. Potts NL, Davidson JR, Krishnan KR, Doraiswamy PM, Ritchie JC (1991) Levels of urinary free cortisol in social phobia. J Clin Psychiatry 52(Suppl):41-42

23. Uhde TW, Tancer ME, Gelernter CS, Vittone BJ (1994) Normal urinary free cortisol and postdexamethasone cortisol in social phobia: comparison to normal volunteers. J Affect Dis 30(3):155161

24. Ahnert L, Gunnar MR, Lamb ME, Barthel M (2004) Transition to child care: associations with infant-mother attachment, infant negative emotion, and cortisol elevations. Child Dev 75(3):639650. doi:10.1111/j.1467-8624.2004.00698.x

25. Rifkin-Graboi A (2008) Attachment status and salivary cortisol in a normal day and during simulated interpersonal stress in young men. Stress 11(3):210-224. doi:10.1080/10253890701706670

26. Bandelow B, Wedekind D, Sandvoss V, Broocks A, Hajak G, Pauls J, Peter H, Ruther E (2000) Diurnal variation of cortisol in panic disorder. Psychiatry Res 95(3):245-250. S0165-1781(00) 00183-9 [pii]

27. Kathol RG, Noyes R Jr, Lopez AL, Reich JH (1988) Relationship of urinary free cortisol levels in patients with panic disorder to symptoms of depression and agoraphobia. Psychiatry Res 24(2):211-221. 0165-1781(88)90064-9[pii]

28. Uhde TW, Joffe RT, Jimerson DC, Post RM (1988) Normal urinary free cortisol and plasma MHPG in panic disorder: clinical and theoretical implications. Biol Psychiatry 23(6):575-585. 0006-3223(88)90004-2[pii]

29. Wedekind D, Bandelow B, Broocks A, Hajak G, Ruther E (2000) Salivary, total plasma and plasma free cortisol in panic disorder. J Neural Transm 107(7):831-837

30. Gustafsson PE, Gustafsson PA, Ivarsson T, Nelson N (2008) Diurnal cortisol levels and cortisol response in youths with obsessive-compulsive disorder. Neuropsychobiology 57(1-2):1421. doi: $10.1159 / 000123117$

31. Kluge M, Schussler P, Kunzel HE, Dresler M, Yassouridis A, Steiger A (2007) Increased nocturnal secretion of ACTH and cortisol in obsessive compulsive disorder. J Psychiatr Res 41(11):928-933. doi:10.1016/j.jpsychires.2006.08.005

32. Monteleone P, Catapano F, Del Buono G, Maj M (1994) Circadian rhythms of melatonin, cortisol and prolactin in patients with obsessive-compulsive disorder. Acta Psychiatr Scand 89(6):411415

33. Weems CF, Carrion VG (2007) The association between PTSD symptoms and salivary cortisol in youth: The role of time since the trauma. J Trauma Stress 20(5):903-907

34. Carrion VG, Weems CF, Ray RD, Glaser B, Hessl D, Reiss AL (2002) Diurnal salivary cortisol in pediatric posttraumatic stress disorder. Biol Psychiatry 51(7):575-582

35. Gunnar MR, Morison SJ, Chisholm K, Schuder M (2001) Salivary cortisol levels in children adopted from Romanian orphanages. Dev Psychopathol 13(3):611-628

36. Goenjian AK, Yehuda R, Pynoos RS, Steinberg AM, Tashjian M, Yang RK, Najarian LM, Fairbanks LA (1996) Basal cortisol, dexamethasone suppression of cortisol, and MHPG in adolescents after the 1988 earthquake in Armenia. Am J Psychiatry 153(7):929-934

37. Strickland PL, Deakin JF, Percival C, Dixon J, Gater RA, Goldberg DP (2002) Bio-social origins of depression in the community. Interactions between social adversity, cortisol and serotonin neurotransmission. Br J Psychiatry 180:168-173

38. Dahl R, Puig-Antich J, Ryan N, Nelson B, Novacenko H, Twomey J, Williamson D, Goetz R, Ambrosini PJ (1989) Cortisol secretion in adolescents with major depressive disorder. Acta Psychiatr Scand 80(1):18-26

39. Dahl RE, Ryan ND, Puig-Antich J, Nguyen NA, al-Shabbout M, Meyer VA, Perel J (1991) 24-hour cortisol measures in adolescents with major depression: a controlled study. Biol Psychiatry 30(1):25-36. 0006-3223(91)90067-V [pii]

40. Guerry JD, Hastings PD (2011) In search of HPA axis dysregulation in child and adolescent depression. Clin Child Fam Psychol Rev. doi:10.1007/s10567-011-0084-5

41. Mathew SJ, Coplan JD, Goetz RR, Feder A, Greenwald S, Dahl RE, Ryan ND, Mann JJ, Weissman MM (2003) Differentiating depressed adolescent $24 \mathrm{~h}$ cortisol secretion in light of their adult clinical outcome. Neuropsychopharmacology 28(7):1336-1343. doi:10.1038/sj.npp.13001841300184[pii]

42. Raine A (1993) The psychopathology of crime: Criminal behaviour as a clinical disorder. Academic, San Diego

43. Zuckerman M (1979) Sensation seeking: Beyond the optimal level of arousal. Hillsdale, Erlbaum, London

44. Cima M, Smeets T, Jelicic M (2008) Self-reported trauma, cortisol levels, and aggression in psychopathic and non-psychopathic prison inmates. Biol Psychiatry 78(1):75-86. doi:10.1016/j. biopsycho.2007.12.011

45. Sondeijker FE, Ferdinand RF, Oldehinkel AJ, Veenstra R, Tiemeier H, Ormel J, Verhulst FC (2007) Disruptive behaviours and HPA-axis activity in young adolescent boys and girls from the general population. J Psychiatr Res 41(7):570-578. doi: 10.1016/j.jpsychires.2006.04.002

46. Marsman R, Swinkels SH, Rosmalen JG, Oldehinkel AJ, Ormel J, Buitelaar JK (2008) HPA-axis activity and externalizing behaviour problems in early adolescents from the general population: the role of comorbidity and gender The TRAILS study. Psychoneuroendocrinology 33(6):789-798. doi:10.1016/j.psyneuen.2008.03.005

47. Keenan K, Shaw D (2003) Starting at the beginning: exploring the aetiology of antisocial behaviour in the first years of life. In: Farrington D, Loeber R (eds.) Causes of Conduct Disorder and Juvenile Delinquency, pp 153-181

48. Kelly SJ, Young R, Sweeting H, Fischer JE, West P (2008) Levels and confounders of morning cortisol collected from adolescents in a naturalistic (school) setting. Psychoneuroendocrinology 33(9):1257-1268

49. Costello AJ, Edelbrock C, Dulcan MK, Kalas R, Klaric SH (1984) Development and testing of the NIMH Diagnostic Interview Schedule for Children in a clinic population. Centre for Epidemiologic Studies, NIMH, Rockville, MD

50. Shaffer D, Fisher P, Lucas CP, Dulcan MK, Schwab-Stone ME (2000) NIMH Diagnostic Interview Schedule for Children Version IV (NIMH DISC-IV): Description, differences from previous versions, and reliability of some common diagnoses. J Am Acad Child Adolesc Psychiatry 39(1):28-38

51. West P, Sweeting H, Der G, Barton J, Lucas C (2003) VoiceDISC identified DSM-IV disorders among 15-year-olds in the west of Scotland. J Am Acad Child Adolesc Psychiatry 42(8):941-949. doi:10.1097/01.CHI.0000046907.27264.E4

52. West P, Sweeting H, Young R, Kelly SJ (2010) The relative importance of family socioeconomic status and school-based peer hierarchies for morning cortisol in youth: an exploratory study. Soc Sci Med 70(8):1246-1253 
53. West P, Sweeting H, Der G (2000) The Voice-DISC: a method for ascertaining psychiatric diagnoses in young people in the community. Occasional paper no 4. Social and Public Health Sciences Unit available at library@msoc.gla.ac.uk, Glasgow

54. Kirschbaum C, Steyer R, Eid M, Eid M, Patalla U, Schwenkmezger P, Hellhammer DH (1990) Cortisol and behavior: 2. application of a latent state-trait model to salivary cortisol. Psychoneuroendocrinology 15(4):297-307. 0306-4530(90)9008 $0-\mathrm{S}[\mathrm{pii}]$

55. Hruschka DJ, Kohrt BA, Worthman CM (2005) Estimating between- and within-individual variation in cortisol levels using multilevel models. Psychoneuroendocrinology 30(7):698-714

56. Lucas CP (2003) The use of structured diagnostic interviews in clinical child psychiatric practice. In: First MB (ed) Review of Psychiatry, vol 22. American Psychiatric Press, Washington DC, pp 75-102

57. American Psychiatric Association (1994) Diagnostic and statistical manual of mental disorders. American Psychiatric Association, Washington DC

58. Aiken LS, West SG (1991) Multiple regression: testing and interpreting interactions. Sage, Newbury Park

59. Preacher KJ, Curran PJ, Bauer DJ (2006) Computational Tools for Probing Interactions in Multiple Linear Regression, Multilevel Modeling, and Latent Curve Analysis. J Educ Behav Stat 31(4):437-448. doi:10.3102/10769986031004437
60. Gordis EB, Granger DA, Susman EJ, Trickett PK (2008) Salivary alpha amylase-cortisol asymmetry in maltreated youth. Horm Behav 53(1):96-103

61. Klimes-Dougan B, Hastings PD, Granger DA, Usher BA, ZahnWaxler C (2001) Adrenocortical activity in at-risk and normally developing adolescents: Individual differences in salivary cortisol basal levels, diurnal variation, and responses to social challenges. Dev Psychopathol 13(3):695-719

62. Young R (2010) Trauma, attempted suicide, and morning cortisol in a community sample of adolescents. J Trauma Stress 23(2):288-291. doi:10.1002/jts.20516

63. Nugent NR, Tyrka AR, Carpenter LL, Price LH (2011) Geneenvironment interactions: early life stress and risk for depressive and anxiety disorders. Psychopharmacology 214(1):175-196. doi: 10.1007/s00213-010-2151-x

64. Yehuda R, Flory JD, Pratchett LC, Buxbaum J, Ising M, Holsboer F (2010) Putative biological mechanisms for the association between early life adversity and the subsequent development of PTSD. Psychopharmacology 212(3):405-417. doi:10.1007/s00213-0101969-6

65. Tyrka AR, Price LH, Gelernter J, Schepker C, Anderson GM, Carpenter LL (2009) Interaction of childhood maltreatment with the corticotropin-releasing hormone receptor gene: Effects on hypothalamic-pituitary-adrenal axis reactivity. Biol Psychiatry 66(7):681-685 